\title{
Behavioural Forensics: Revelations from CNX Nifty Analysis
}

Pooja Ramesh Golait*

\section{Abstract}

Economic growth and sustainable development in financial markets are only possible when the firms show robustness and stability through the ethical way of business. However, it has been observed that certain firms take incorrect measures while running their business. This work attempts to detect threads of possible financial frauds by Didier Sornette's drawdown approach. Select CNX Nifty 50 Mid Cap stocks are shown here as samples. Drawdown approach identifies the breakpoints and clearly detects the dates and could be linked to the anchoring and herding behaviour in certain cases. Apart from that, other financial or strategic events could be linked as well. Qualified institutional buyers and large institutional investors can use this method as a corporate governance crosscheck, from an entirely different standpoint.

Keywords: Drawdown Approach, Behavioural Forensics, CNX Nifty 50 Mid Cap stocks

\section{Introduction}

Behavioural Forensics understands the nature of the fraudulent activities and how this impacts the stock market fluctuations. This includes various participants of the institution i.e. their management, board, directors, employee and so forth. This becomes important to detect the stock fluctuation and fraudulent practices in an institution. Nifty 50 Mid Cap is one such index which is being traded on a large scale in India. There are many

*Moody's Analytics, India; prggrp.16@gmail.com 
investors for trading, investing, portfolio, thematic portfolio, etc. As this index is used widely, the companies contributing to this should also be strong in their ethics and financial health. Forensic is an emerging field and behavioural forensic understands the pattern of the movement of stock and traces back the fraudulent actions that have taken place. There can be both internal and external reasons contributing to this. The nature of the stock movements depends upon the health and trading pattern of the company. Nifty $50 \mathrm{Mid}$ Cap companies become a benchmark for many investors to trade, invest, create portfolios, etc. Hence, understanding the health of the companies contributing to this index becomes an important area of study. There are different methods to understand the stock fluctuations of companies. Behavioural Forensics is one such method which helps to identify the health of the company and its various behaviours. Under normal or abnormal circumstances, the fluctuations of the stock market have a significant implication for the investors to understand the company's stock movement. Hence, this becomes a major part of a forensic study.

To detect irregular trading patterns, a mathematical model proposed by Didier Sornette in his book "Why Stock markets Crash?"(Sornette, 2003) has been used. The mathematical model consists of drawdowns which can be used to trace the insider information which led to breakeven points. To highlight fraudulent movements, a specific time period is taken to understand the fluctuations in detail. This is done to understand stock fluctuations by backtracking it to trace the reasons for such a pattern. This mathematical model not only tells about the critical break-even points but also talks about the health of the company which is a contributing factor to the Nifty 50 Index. In fact, by tracking the fluctuations and pattern predictions of the past irregularities, investors who depend on these stocks understand the strength of the stock. Investors tend to invest less to avoid loss when there is an increase in volatility.

\section{Literature Review}

Sornette and Johansen (2001) proposed that stock market crashes have their traces to critical points of log periodic curves. This is proved by a model which describes the stock market prices before 
and after the crisis. This test was done on the two largest crises of the 20 $0^{\text {th }}$ century - October 1929 and October 1987. The authors conclude their study with the proposal of "Crowd Behaviour" which shows how multiple agents participate in stock market trading. Laloux et al. (1998) proposed a non-linear Langevin equation to depict a model for market fluctuations and crashes. The equation formulated by Langevin is based upon an identification of processes that indirectly or directly depends upon demand and supply. It also includes the mathematical formulation for various other factors which influence stock market fluctuations and crashes. Authors highlighted the significance of feedback effects of price fluctuations in their theory. Risk aversion leads to an updown irregularity flouting period which is accountable for crashes. There are various factors on which both the crisis are dependent separately.

Daniel, Knetsch and Richard proposed (Benartzi et al., 1993) that economies of the firm follow a standard economic model, but it should be replaced by realistic behavioural assumptions. In this journal, the authors have complicated the economic model and made it complex for more accurate calculations which will help the profit-seeking opportunities of the firm. The absence of the fairness of the standard economic model keeps many aspects hidden and therefore a correct judgement is not adopted. Lux, Thomas and Marchesi (1999) have proposed the contradictions in 'efficient market hypothesis'. Financial prices resemble the characteristics of the scaling law of physics (Marchesi, 1999). But this is different from EMH which say that financial prices do not depend on past trends and incoming news. The authors described this hypothesis with their mathematical model that scaling theory is significant as financial asset prices change with multi-agent interactions. The power law has also been proposed in this paper. Lux, Thomas and Marchesi (1999) have observed the contradictions in 'efficient market hypothesis'. Financial prices resemble the characteristics of scaling law of physics (Lux, Thomas \& Marchesi (1999). But this is different from EMH which say financial prices do not depend on the past trends and incoming news. The authors described this hypothesis with their mathematical model that scaling theory is significant as financial asset prices change with multi-agent interactions. Power law has also been proposed in this paper. 
Jiang et al. (2016) conducted research on short term prediction of extreme returns based on the recurrence interval analysis. The research paper identifies important issues in financial risk management. In financial risk management, the ability to predict the existence of extreme returns is a significant element. The researchers have identified that predicting the occurrence of extreme results is possible in the short term and they have used the spreading of recurrence intermissions, that is, the waiting time between consecutive extremes for understanding the same.

Sornette and Cauwels (2014) argued that a financial bubble is barely well understood and its meaning is subject to controversy and debates. Bubbles refer to the phenomena where the price of an asset, in a series of accelerating phases of corrections and rebounds, increases ever more quickly. Financial bubbles leave their exact traces making them recognisable in loan and can help the relevant parties to identify them before they burst. The similarity of behaviour that a group of units follow is known as the coupling effect. This effect can reveal the character of the data one is using. The nature of the data also differs due to its environment in which it stays. This understanding can be considered when one is exploring the stocks and the sectors to which it belongs to. The impact of the environment refers to the idea that the impact of economic events has the tendency to fluctuate the stock price.

Kahneman, Knetsch and Thaler (2016) proposed that there are market anomalies due to which firm tend to cut or raise prices. The reason that the firm gives should be fair when compared to market conditions. The firm's maximum profit policy is an important landmark. But there are unexpected losses due to market constraints which are known or unknown. Gaunersdorfer (2000) argues that traders in the stock market have different expectations from the future price of the stock and take a purchase decision according to the situation and demands. They also know their risk appetite and trade accordingly. In real time trading, several issues become significant and insider trading information or events prove important. Therefore, market fluctuations can be studied in more than one way. Diba and Grossman (1988) proposed that the stock bubble and rational market are fundamental for understanding the stock market volatility. They say that the behaviour of the assets 
depends on one or more variables. It is also being argued that the rational bubble is not directly correlated to asset price fluctuation and rather has some coefficient associated with it. Previous research highlights prior work on testing the bubble or individual stocks (Ghosh, 2016). Similarly, research on sentiment analysis posits the presence of profound traces of sentiment across various market segments (Ghosh \& Srinivasan, 2014, 2015; Ghosh, 2017). Additionally, various behavioural traces were found in most of those cases. However, their impact wasn't specifically visible. This study bridges the gap.

\section{Methodology}

The study is conducted on the Nifty Mid Cap 50 Index. There are 50 stocks in this index comprising of different sectors. These stocks are individually analysed and then considered as a whole including elements from different sectors. The objectives of this study are as follows:

I. To understand the performance of individual stocks in Nifty Mid Cap 50 Index

II. To know the investment strategies in these stocks based on their corporate governance.

The researcher has used secondary data collection method for the study. The data is taken from NSE historical data. The time period of the data is from 2002 January till November 2017. The methodology used for index calculation is also mentioned in NSE. Free float market capitalisation is used to calculate index using 50 Mid Cap stocks.

The data set consists of six columns namely Date, Open, High, Low, Close and Adjusted Close. The main requirements from this data set are Date, Close and Adjusted Close. Drawdowns and Returns can be calculated on the basis of these 3 data points. Mostly all the stocks consists of 3754 rows except few stocks whose registration date with NSE is after January 2002 will vary. For this study, to understand the performance of NIFTY 50 stock index, an individual company's drawdowns are analysed. A drawdown is defined as a persistent decline in the value over successive days. A 
drawdown is thus the increasing loss from the last maximum to the following minimum of the price. Drawdowns are pointers that we are concerned about: they measure in a straight line the accumulative loss that an outlay may suffer. Five such stocks have been shown in this paper.

Step1:

Drawdown $= \begin{cases}1, & s_{i}<s_{i-1} \\ 0, & s_{i}>s_{i-1}\end{cases}$

Where, $s_{i}$ represents 'adjusted close' of the stock today and $s_{i-1}$ represents the same for yesterday.

Step 2: Calculation of 'Cumulative Drawdown'

Step 3: Natural Logarithm of 'Cumulative Drawdown', this represents 'Risk' (Independent variable)

Step 4: Return of the stocks for the same days

Step 5: Calculation of 'Cumulative Return'

Step 6: Natural Logarithm of 'Cumulative Return'; this represents ‘Return'(Dependent variable)

Step 7: Plot and track the 'breakpoint'; match the 'breakpoint' with the date

Step 8: Post 'Breakpoint', the risk is increasing ( $\mathrm{x}$-axis) however return is decreasing (y-axis); this is unnatural and sends a clear 'forensic alert'. If any significant policy change, financial declaration or international event effect is not visible, then the 'forensic alert' is taken more seriously to examine further.

\section{Results and discussion}

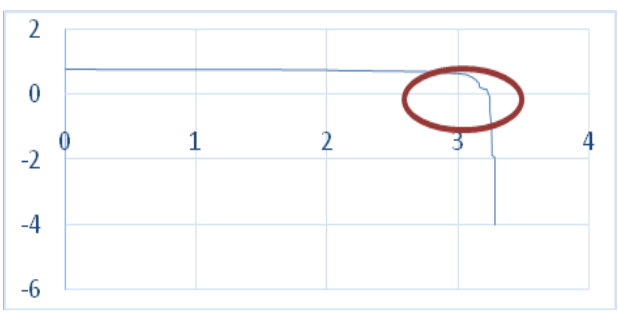

Graph 1 Adani Enterprises 
Adani Enterprises is a part of the Adani Group. The business is spread across coal trading, agro-business, renewable energy generation, etc. it was listed in NSE in August 2002. When its stock data was verified under the mathematical formula it had a breakeven point or reached the critical point at 3.097. Adani Enterprise witnessed 80\% fall in its share prices in early June 2015, which matches with this forensic alert. Port and Solar business got demerged and the company was left to focus on Coal business alone. This confirms that no financial irregularities were present.

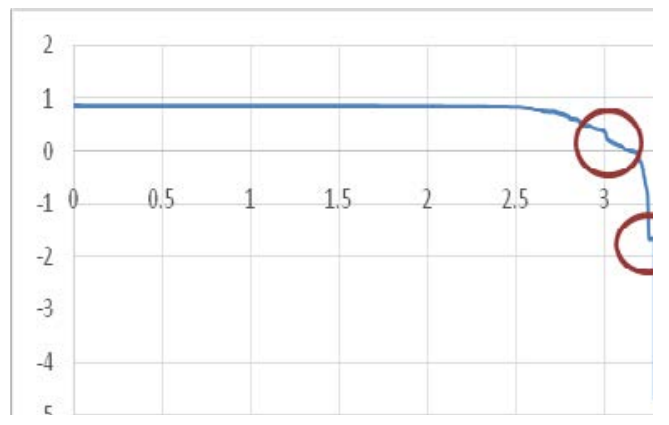

Graph 2 Ajanta Pharma

Ajanta Pharma is one of the big Pharma firms in India which manufactures and markets pharmaceutical formulations. It is a public company. It was listed on NSE in July 2002. This company has a good history and trades with 30 more countries all over the world. When the mathematical model was run on the stock data, the critical point was found out to be at 2.606. After which fluctuations could be seen at one point that is, 3.249. By trying to trace the data by expanding it, no fluctuations could be seen. This is because there were stock fluctuations due to market news. On 21 August 2017, there was a government policy declaration in the pharmaceutical sector. The policy was about loan licensing to be phased out for more than three years except in Biopharmaceuticals. Due to this reason, the entire Pharma sector stocks came down. Hence, the financial irregularity could well be due to the government policy. 


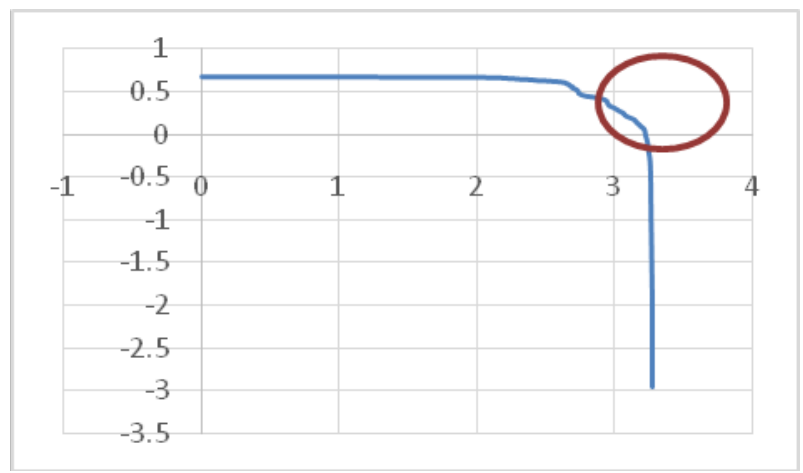

Graph 3 Arvind Ltd.

Arvind Ltd manufactures high-end fabrics. It was started in the year 1931. Arvind was one of the forefronts in their business as they improved their fibre quality and subdivisions year after year. A maximum number of shareholders are promoters which comprise $42 \%$ of their shareholders' population, followed by FII. After running Arvind stocks through the mathematical model, its critical point came around 2.898. In July, when their annual report was announced, there were few turbulations. Generally, annual reports do bring in uncertainty which affects the risk-return equation. Hence, the possibility of financial irregularity could be ruled out with this prima facie evidence.

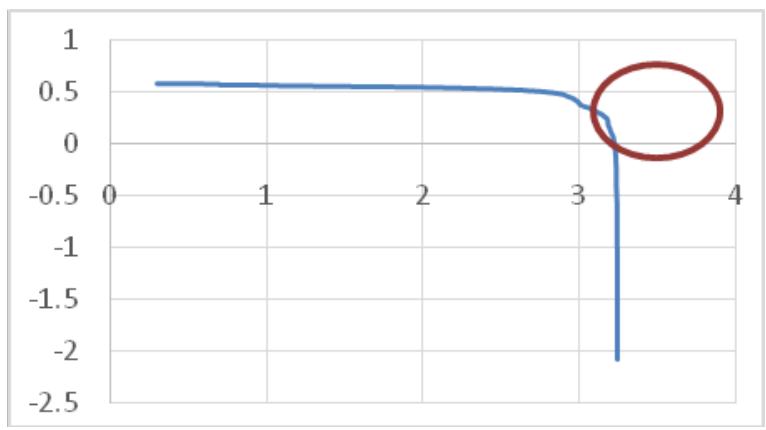

Graph 1.3 Canara Bank

Canara bank is a public sector bank which is under the Government of India. It was founded in the year 1906 in Mangalore. After running the bank's data in the mathematical 
model, the critical point was found at 3.108. Since the date coincides with that of its annual reports, volatility could be expected. Generally, annual reports do bring in uncertainty which affects the risk-return equation. Hence, the possibility of financial irregularity could be ruled out with this prima facie evidence.

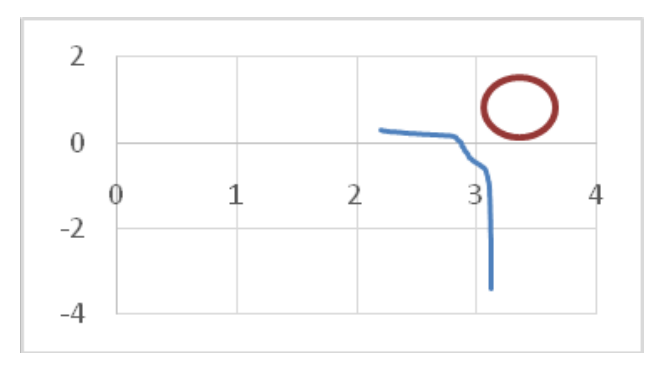

Graph 1.4 Indraprastha Gas Ltd

IGL is a public company which is leading in Gas Distribution in India. Its headquarters is in Delhi and it was founded in the year 1998. BPCL is the promoter holding the highest number of shares at around $22.5 \%$. When the stocks data were run in the mathematical model, it was seen that the slope gradually falls down after 2.84 after which it is falling down to the next critical point 3.071, beyond which it breaks down. During these two points, there are slight lowering values. This is indirectly affected because of the maximum shareholders of BPCL. This was during the period $24^{\mathrm{Th}}$ August $2010-5^{\text {th }}$ September 2010. During this period, R K Singh was appointed as the new Chairman and MD of BPCL. Soon, he decided to acquire a stake in two shale acreage from Australia. Business decisions and expansion plans do result in undue volatility. Hence, a forensic alert will not indicate any significant financial irregularity in this case as well.

\section{Overall Analysis}

CNX Nifty Mid Cap 50 consists of fifty stocks with mid-market capitalisation. To know how the index movement is and the efficiency of the index, one can combine the understanding of individual 50 stocks. After analysis, 1 out of 5 companies has been detected with possible financial irregularities which bought 
changes in the stock price drastically or slowly over a period of time. Though the sample is on the lesser side, yet it could be well be confirmed that no financial irregularity or possible fraud has been found. Moreover, that could be predicted well in advance with 'forensic alert' using Drawdown methods.

\section{Conclusion}

The purpose of the investor is to invest in relatively robust companies, in a fundamentally sound sector backed by capable management and efficient corporate governance. Investing in Nifty Mid Cap stocks, as the majority of the stock have good corporate governance, provides a greater opportunity for growth in investments. Basically, Mid Term index stocks gain more in the long term rather than short term. From past records of 5 years, it is seen that the index return is $18 \%$. Mid Cap stocks have less research coverage and in addition, many people can afford these stocks. There is diversification of more than 20 sectors in this index which again balances the loss for the investor from a portfolio perspective.

The method by Didier Sornette helps in understanding corporate governance, frauds in the stock and the overall performance which in turn comments on the on-going condition of the company and how it can progress. Equity investors seeking long term investment or long term wealth creation with investment opportunity looks forward at stocks with a moderate to aggressive risk appetite. The investment horizon spans from 3 to 8 years. It is seen that in different cycles of bulls and bears, the impact is not on a large scale. The Systematic Investment Plans is a good investment strategy wherein he/she can use this index. In spite of the implementation of demonetisation (India) and GST, the two biggest events which happened recently, the impact is not visible on these stocks. Few stocks have been affected, but the efficiency of the index is more than $80 \%$, which in real time scenario, is better than normal. There can also be a huge valuation gap between Current Market Price and Actual Value as these stocks have not been studied much. In many stocks, where the majority of shareholding is a single entity of VC, an impact in stock volatility is seen. 


\section{References}

Behzad T. D. \& Grossman, H.I. (1988). American Economic Association: Explosive rational bubbles in stock prices? The American Economic Review, 78(3), 520-530.

Benartzi, S., \& Thaler, R. H. (1993). Myopic loss aversion and the equity premium puzzle (No. w4369). National Bureau of Economic Research.

Sornette, D. (2003). Why markets crash (1st ed.). Princeton University Press.

Gaunersdorfer, A. (2000). Endogenous fluctuations in a simple asset pricing model with heterogeneous agents. Journal of Economic Dynamics and Control, 24(5-7), 799-831. https://doi.org/ 10.1016/ S0165-1889(99)00026-3

Ghosh, B., \& Srinivasan, P. (2014). BSE 100 Market Capitalization follows Sentiment of Investors or Technical Methods-An analytical study. Scholarly Research Journal for Humanity Science and English Language, 1(3), 400-404.

Ghosh, B., \& Srinivasan, P. (2015). Detection of sentiment in CNX NiftyAn investigative attempt using probabilistic neural network. International Journal of Business Quantitative Economics and Applied Management Research, 1(12), 1-11.

Ghosh, B. (2016). Rational Bubble Testing: An in-depth Study on CNX Nifty. Asian Journal of Research in Banking and Finance, 6(6), 10-16.

Ghosh, B. (2017). Quest for Behavioural Traces the Neural Way: A Study on BSE 100 along with its Oscillators. Indian Journal of Research in Capital Markets, 4(1), 19-25.

Jiang, Z.-Q., Wang, G.-J., Canabarro, A., Podobnik, B., Xie, C., Stanley, H. E., \& Zhou, W.-X. (2016). Short term prediction of extreme returns based on the recurrence interval analysis.

Johansen, A. \& Sornette, D. (2001). Bubbles and anti-bubbles in LatinAmerican, Asian and Western stock markets: an empirical study. International J. Theoretical \& Applied Finance, 4, 853-920.

Kahneman, B. D., Knetsch, J. L., \& Thaler, R. H. (2016). Fairness as a constraint on profit seeking : entitlements in the market. The American Economic Review, 76(4), 728-741.

Laloux, L., Potters, M., Cont, R., Aguilar, J. P., \& Bouchaud, J. P. (1998). Are financial crashes predictable? Europhys. Lett., 45, 1-5.

Lux, T., \& Marchesi, M. (1999). Scaling and criticality in a stochastic multiagent model of a financial market. Nature, 397(6719), 498-500. https://doi.org/10.1038/17290

Sornette, D., \& Cauwels, P. (2014). Financial bubbles: mechanisms and diagnostics. Cornell University Library, (January), 1-24.

Tversky, A., \& Kahneman, D. (1973). Availability: A heuristic for judging frequency and probability. Cognitive Psychology, 5(2), 207-232. 